\title{
SOBRE INTERPRETACIONES POSIBLES DEL DERECHO Y DE LOS TEXTOS DE ENRIQUE P. HABA*
}

\author{
Juan Antonio García Amado \\ Universidad de León
}

RESUMEN. Juan Antonio GaRcíA AmAdo y Enrique P. HABA debaten sobre la objetividad de la interpretación en un intercambio epistolar. Su debate se publica en los dos siguientes artículos. En el primero GARCÍA AMADO defiende una objetividad interpretativa negativa de acuerdo con la cual aunque no se puede sostener que exista una única interpretación correcta, sí puede afirmarse que existen interpretaciones imposibles.

Palabras clave: Interpretación jurídica, objetividad.

\section{On Possible Interpretations of the Law and Texts of Enrique P. HABA}

ABSTRACT. Juan Antonio GaRcíA AMADO and Enrique P. HABA debated on objectivity of legal interpretation in an exchange of letters. Their debate is published in the two following articles. In the first one, GARCíA AMADO is committed to a negative interpretative objectivity to the extent that he consideres the just one correct interpretation claim unfounded but accepts that certain interpretations might certainly qualify as impossible.

Keywords: Legal Interpretation, objectivity.

*Fecha de recepción: 6 de marzo de 2015. Fecha de aceptación: 5 de septiembre de 2015. 


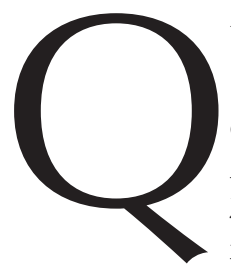

uerido Enrique:

Es complejo y lleno de recovecos este documento en que comentas el debate entre Manolo y yo (M. ATIEnZA RodríGueZ y J. A. GarCía AMADO, Un debate sobre la ponderación, Lima-Bogotá, Palestra-Temis, 2012, 138 pp.), tomando pie (con toda legitimidad y todo derecho, ni más faltaba) para hacer nuevo hincapié en tus críticas al pensamiento jurídico establecido y cultivado por los que somos aficionados al storytelling, en sus diversas variantes y grados, y para reiterar aspectos muy sustanciales de tu propia manera de entender lo jurídico y su teoría (y su práctica). No puedo o no me veo capaz de entrar en una consideración muy pormenorizada de las muchas ideas que apuntas en tu trabajo, sea en la parte de crítica o en la de propuesta y construcción. Así que, disculpándome, me detendré nada más que en algún que otro punto, bien porque se trate de discrepancias, bien porque me surjan problemas de comprensión de tu postu$\mathrm{ra}$, o por ambas cosas.

1. Tomemos este escrito tuyo, «A revueltas con la Storytelling...» ${ }^{1}$, y, si queremos jugar con una hipótesis más cerrada, supongamos que este artículo, amén de ser muy importante, constituyera toda tu obra iusfilosófica (bien sé yo de la amplitud e importancia de tus escritos, que debo de haber leído con provecho - iaunque tú consideres que no con provecho suficiente!- en un mínimo del 90 por 100). Tú en el referido artículo dices una serie de cosas, algunas de las cuales yo comprenderé quizá con dificultad y otras de las cuales creo que entiendo muy bien, las comparta o no. Te pongo algún ejemplo, el más simple, de cosas que tú dices y cuyo sentido yo entiendo plenamente:

i) «Querido Juan Antonio: He leído íntegramente, y con toda atención (creo), el librito que tuviste la gentileza de mandarme» (primer párrafo de tu escrito) ${ }^{2}$.

ii) También «en los discursos inspirados [...] como unos que, mutatis mutandis, tan bien ilustra el filme de Woody Allen, The Purple Rose of Cairo» (núm. 1)3.

Verás enseguida por qué uso dos ejemplos tan sencillitos. Pues te pregunto: ¿puedo yo entender, sin que alguien me tome por loco o tramposo compulsivo o ignorante del idioma español, que en i) me estás contando que acabas de leer el último libro de FERRAJOLI, o que del librito de Manolo y mío no has leído nada más que las diez primeras páginas o que te pareció una grosería que yo te enviara ese libro? ¿Puedo yo entender, sin que alguien piense que he perdido la cabeza o que ando en alguna sucia maniobra contigo, que la analogía que en ii) trazas para ciertos discursos de juristas o profesores queda bien ilustrada en la película Ben-Hur?

Supongo que a esas muy elementales preguntas me vas a responder que no, que no puedo entender eso sin que de inmediato afirmes y afirme cualquiera que tergiverso absolutamente el significado de tus frases y términos. ¿Y si yo digo que estoy interpretando esas frases y términos? ¿No me responderías que esas mías no son interpretaciones posibles de tus enunciados? Pues entonces es que sí podemos diferenciar entre

1 E. P. HABA, «A revueltas con la storytelling llamada "ponderación", y también preguntando sobre "límites" del derecho», Doxa, núm. 37, 2014, 337-373.

2 Loc. cit., 339 in limine.

3 Loc. cit., 340: en el párr. 2. ${ }^{\circ}$ de ese número. 
interpretaciones posibles e interpretaciones no posibles. Porque si no pudiéramos, no tendría sentido que nos comunicáramos, y menos todavía que nos hiciéramos reproches por entendernos mal o alterar por completo lo que dice el otro.

También hay cosas que tú no dices. Por ejemplo:

iii) No dices que FERRAJOLI sea un tremendo asesino que se dedica últimamente a recorrer, por las noches, las calles de Roma estrangulando a inocentes viejecitas ingenuas. No lo dices, pero yo podría interpretar que ése es el sentido de fondo o lo que tratas de expresar en un párrafo en el que aludes a las axiomatizaciones de FERRAJOLI y a la «rotunda endeblez» de sus planteamientos (nota al pie núm. 13 in limine) ${ }^{4}$. ¿Acaso no es posible que yo interprete eso? Si me contestas que no es posible es porque, igual que yo, diferencias entre interpretaciones posibles y no posibles. Si me respondieras que sí cabe perfectamente que yo haga aquella interpretación, me darán tentaciones de interpretar libérrimamente cada frase de un libro o artículo tuyo, y sería el caos; me estarías legitimando para sostener, por ejemplo, en cualquier congreso de nuestro gremio, que entre los más radicales defensores actuales del iusnaturalismo teológico se halla el profesor Enrique HABA ¿Por qué no? De becho cabe que haya quien lo pueda entender así porque quiera desprestigiarte o porque sea un memo.

2. Llegamos a un punto en el que siempre encuentro un límite en tus tesis, y casi te ruego que no me regañes por no recordar o no saber ver ahora que esas dudas mías ya las dejaste resueltas en un libro de hace veinte años. El punto es el siguiente:

Tomemos de nuevo tu obra y pongámosla en el contexto de nuestro mundo académico. Estarás conforme conmigo en que muchos de los que la han leído la habrán entendido mal en partes sustanciales (¡yo mismo, según algún amargo reproche tuyo, no te digo que carente de razón, no sé!) y me parece que tales incomprensiones o malas comprensiones, sean por la mala cabeza de unos o por lo que les molestas a otros con tus críticas, provocan en ti algo de indignación a veces. ¡Tienes toda la razón para ello! Ahora bien, yo podría replicarte que:

a) Ya sabes cómo es la comunidad académica, un entramado gelatinoso de intereses, malos quereres, celos gremiales, luchas palaciegas, ignorancia camuflada, gusto por el poder, deseo de estar a bien con los que mandan y reparten juego, dificultad intrínseca de las teorías, cambios sociales que a veces dejan en fuera de juego al profesorado mejor y sus obras, etc. Estaría yo así describiendo lo que es un hecho o conjunto de hechos que me parecen bien claros, y pienso que tú estarías bastante de acuerdo conmigo en tal descripción de esos hechos o de esa situación de hecho.

b) No tienes que molestarte porque, dados esos hechos y que las cosas son de ese modo, no hay en verdad algo así como el contenido objetivo de la obra tuya ni un límite tangible a las interpretaciones posibles de la misma. Es más, cuando tú te defiendes frente a los que te imputan tesis o afirmaciones que no hiciste, te pones al nivel de los cultivadores del «storytelling». ¿Y si te dijeran que no importan las palabras de tal o cual sitio, sino que o bien interesan las razones del intérprete más que nada o bien en realidad no existe más obra académica que un maremágnum, hermenéuticamente procaz, de interpretaciones, maniobras y decisiones? Yo podría parafrasearte [núm. 3.a),

\footnotetext{
4 Loc. cit., 351.
} 
al comiendo de su tercer párrafo] diciendo esto: «A mí, la semántica de Haba —o la semántica del campo científico o teórico que cultiva Haba- no me interesa en sí y por sí ("novelas de conceptos"), sino únicamente en tanto en cuanto ella sea capaz de co-determinar — ¡o no!- la pragmática (¡repercusiones sociales efectivas!) de los discursos en cuestión» ${ }^{5}$.

Para mí, la prueba de que no tendría razón yo mismo al alegarte eso que acabo de escribir en $a$ ) y $b$ ) es que te estoy escribiendo, y si las cosas fueran así y así las pensara, me callaría, por coherencia y para no perder el tiempo.

Y entonces pregunto: si cuando Enrique HABA afirma que los planteamientos teóricos de FERRAJOLI son rotundamente endebles ${ }^{6}$ no puedo entender o interpretar que Enrique HABA afirma que FERRAJOLI es un asesino que transita nocturnamente por las romanas calles a la busca de viejecillas desprevenidas, ¿por qué no puedo sostener que también hay un límite a las interpretaciones posibles de una norma jurídica, presente en una ley en vigor, y que dijera «Queda prohibido, bajo sanción S, fumar en el interior de los hospitales»?

¿Acaso si yo describo la práctica de la comprensión y la interacción académica y la describo certeramente en los términos antedichos tengo yo (y tienes tú) que aceptar que lo que nosotros decimos y escribimos no es lo que nosotros decimos y escribimos, sino lo que se entienda y se use en esa práctica y que, por tanto, cuando tú y yo escribimos de derecho, en realidad no escribimos de derecho, porque el derecho es una práctica y nosotros no practicamos, sino que escribimos?

3. Pongamos que tú consideraras un día que el sentido de lo que expresas en tus trabajos está siendo fuertemente deformado por un grupo de profesores que se empeñan en ver en ti un iusnaturalista escolástico o un dworkiniano parapetado. Puedo suponer que, puesto a fundamentar tu postura y ante las preguntas de los que estuviéramos interesados en la polémica, tú quizá aludirías a que existen unas reglas mínimas de honestidad en el trabajo académico y que rigen también a la hora de reproducir y catalogar lo que proclamamos los profesores. Añádase que, según algunos de aquéllos que en mi ejemplo adulteran tus tesis, no importa en realidad la letra de tus escritos y no vamos a creer en semánticas firmes ni en reglas lingüísticas terminantes, razón por la cual cabe perfectamente, como interpretación de tus palabras, una que las haga significar lo contrario de lo que con ellas entiendes tú o entendería un hablante normal de nuestro idioma o un profesor cabalmente imparcial, si es que esa figura puede darse. Y que, según otros de ese grupo de manipuladores, no es que se pueda dar o no la vuelta a las palabras, sino que hay que ir a lo que muy por debajo de ellas subyace, a los valores que aportan razón de ser a la comunicación en general y a la académica en especial, de forma que no tendría sentido pensar que alguien está expresando verdaderas ideas académicas cuando se equivoca tan patentemente como tú al criticar el iusnaturalismo y los variados iusmoralismos. De modo que la única manera de salvar tu obra, según tal punto de vista, y de mantenerla como una obra académicamente importante, es haciéndote en el fondo decir lo que tus palabras no dicen; esto es, que está muy bien el iusnaturalismo y que DwORKIN, luminoso en su

\footnotetext{
5 Loc. cit., 345.

6 Supra, n. 4.
} 
oscuridad y preciso en sus incongruencias, tiene mucha más razón que todos los positivistas y realistas juntos.

Bien, ése es el ejemplo para jugar. Entonces, y para seguir jugando, supón que algún colega que sabe de nuestra ya vieja amistad acude a mí para que tercie yo en la polémica y a tu favor dictamine. Por ganas, simpatía y acuerdo profundo con muchas de tus tesis, yo lo haría encantadísimo. Pero a lo mejor me venían dudas de si no metería la pata al defender que hay unas reglas del trabajo científico y académico serio que esos otros profesores malandrines están vulnerando. ¿Por qué dudaría? Porque alguien puede pedirme que enuncie alguna de esas reglas y yo aludiría, mismamente, a la de que «no se puede poner en boca de un profesor lo contrario de lo que él dice y escribe sobre los temas de su especialidad», pero en menudo atasco me mete si a continuación ese malévolo interlocutor me enseña los textos tuyos en los que dudas de que esté acotado el campo de las interpretaciones posibles de una regla como ésa, supuesto que efectivamente esté vigente, o el campo de las interpretaciones posibles de cualquier fragmento de un libro tuyo.

Segundo, puedes imaginar mi desconcierto si, en ese contexto, me leen el trozo de tu escrito que comentamos (núm. 8, párrafo inicial) en el que haces ver que ni Manolo ni yo fundamentamos nuestras tesis «en la medida de lo posible, en observaciones empíricas de racionalidad instrumental ${ }^{7}$. O sea, que para defender yo las reglas aquellas que violan los que manipulan tu doctrina y para defenderte a ti mismo bajo esas reglas, debería dedicarme a buscar «factores conductuales reales comprobados» (ibid.). Bien, los busco y descubro que hay mucho supuesto profesor y académico que es una mala bestia y no entiende nada o lo entiende todo al revés, que habla sin leer y opina sin conocer, etc. Y después de constatar eso que, por cierto, es muy fácilmente constatable y hasta por mi abuela conocido, ¿qué hago yo respecto de la regla aquella del trabajo científico y respecto de tu caso? ¿Concluyo que estaba yo mismo equivocado al creer en reglas y en su sentido o en lo limitado de sus interpretaciones posibles y al no darme cuenta de que esas reglas en realidad bien poco atan o significan, puesto que está todo lleno de «factores conductuales reales comprobados» que hace con tales reglas lo que les da la gana?

Cabe que un crítico de mi ingenuidad y de mi uso persuasivo de las reglas, los lenguajes y las racionalidades no instrumentales venga con tu texto y me indique (ibid., párr. $2^{\circ}{ }^{\circ}$ que, en efecto, ando yo buscando «una inveterada cuadratura del círculo: la postulación de que puede haber ciertos criterios propiamente objetivos, ya sean unos $\mathrm{u}$ otros, para definir los conflictos de interpretación entre los juristas» ${ }^{8}$. Y, entonces, alguien menos terco o curtido que yo mismo diría que de acuerdo y que cómo va él a seguir insistiendo en que sí hay unos criterios objetivos para diferenciar cuándo alguien hace una interpretación posible y razonable de un texto tuyo y cuándo cae en una interpretación errónea e inasumible al imputar a dicho texto tuyo el sentido que más le apetezca o le convenga, en función de los factores conductuales de guardia. Fíjate, en la frase anterior he dicho «posible y razonable» y ya me vienen los sudores pensando en cómo rechazarías tú esa defensa tuya mediante esa forma mía de argumentar.

\footnotetext{
7 Loc. cit., 358.

8 Loc. cit., 358.
} 
Es que al leer esa página tuya me doy cuenta de que por mucho que yo me empecine en que en la página $\mathrm{X}$ de una obra tuya tú has dicho y querido decir que DwORKIN es un autor metodológicamente endeble, concretamente en aquella frase (la invento) en que tú literalmente decías que «Dworkin es un autor metodológicamente endeble», y que endeble no puede significar «magnífico y ejemplar», si te hago caso tendré que admitir qué vaya usted a saber, pues mi insistencia en que hay significados objetivos podría ser tildada de «comodín retórico» ${ }^{9}$ y tú me señalarías que carezco, en lo que a la interpretación y los significados se refiere, de criterios «susceptibles de acreditación inter-subjetiva ${ }^{10}$. Porque supongo que no me vas a contestar que para la interpretación de tus escritos sí concurren todos los factores de objetividad, verdad y corrección que para la interpretación de los textos jurídicos faltan. Te tengo en mucho, pero cuando te leo no veo tus frases como pertenecientes a un reino ontológico distinto de aquél al que pertenecen los enunciados de la Constitución o del Código Penal. Sigamos con la broma: me podrías decir que tú eres tú claramente, mientras que las fronteras de lo jurídico son equívocas y es propio de idealistas irremediables andar buscándolas. Pero si me haces escéptico y me obligas a sospechar, ya no podré detenerme: ¿cómo puedo yo o cómo puede estar cualquiera seguro de que tú eres en verdad tú y no el heterónimo de algún cantante de tangos o un robot experimental de una multinacional japonesa?

Lo que sucede, creo, es que debemos responder a esta pregunta: cuando yo afirmo que «metodológicamente endeble» no puede significar o ser interpretado como equivalente a «metodológicamente magnífico y ejemplar», ¿estoy haciendo un enunciado descriptivo o normativo? Yo diría que normativo, pero basado en el hecho de que la mayor parte de los usuarios actuales de nuestro idioma lo entenderían así, y también en la consideración de que si cada cual va a poder entender cada palabra como le da la gana, no habrá comunicación lingüística posible. Tú dirás que esto es idealismo y comodín retórico, pero entonces yo te pregunto qué base tienes tú para indignarte cuando alguien interpreta completamente al revés una de tus frases. Porque, si lo que cuenta es lo empírico, lo fáctico y conductual, a tu enfado yo responderé: Enrique, no seas idealista y retórico y déjate del storytelling, porque no puedes negar que Fulano y Mengano (y 20 más, quizá), han entendido de aquella otra manera tu frase y, por tanto, objetivamente no puedes decir que tu frase significa lo que para ti y para mí significa o puede significar sin violentar unas reglas semánticas que, en tu opinión, son cosa de crédulos y personas sin los pies en la empírica tierra. ¿O acaso para tus escritos y su significado posible o para el trabajo científico-doctrinal en general sí vale alguno de esos «mundos geométricos donde anidan las certezas lingüísticas» aun en cuanto a usos lingüísticos que son controversiales en la práctica - la creencia en unos significados que serían, pues, «supraconvencionales»-? (en el párrafo donde está la n. 19) ${ }^{11}$.

Por cierto, yo no creo en significados supraconvencionales, pero creo que el valor normativo (¡idealismo!) o el significado social o la función social de las convenciones se mantiene aun por encima de unas cuantas excepciones, del hecho de que haya quien no se atenga a las convenciones. Que a mí se me pueda llamar español es fruto indudable de una convención. Que un tipo se empecine en que soy chileno o en que

\footnotetext{
9 Loc. cit., 359 in limine.

10 Loc. cit., 358 in fine.

11 Loc. cit., 359.
} 
«español» significa lo mismo que «chileno» no le quita ningún valor o ninguna fuerza a la convención de marras. Igual que si la norma jurídica dice «bigote» no puede estar refiriéndose a un avión o a un tren, os pongáis tú y Manolo como os pongáis, él porque lo importante son los valores y tú porque en qué quedan las convenciones lingüísticas si hay gente que por oscuros intereses o idiocia no las atiende.

Porque, Enrique, a lo mejor me dices que en el párrafo anterior simplifico o tergiverso yo tu postura, y tal vez así sea, pero en cualquier caso no puede ser la misma que en mí criticas, y lo que en mí criticas es que confío «en que existe un cuadrado circular donde estarían localizados los «límites» objetivos pre-establecidos como sentidos «posibles» del derecho aplicable» ${ }^{12}$, o que así lo creo al menos en algunos casos. Si tú no lo crees ni siquiera «en algunos casos» (un poco después de la n. 19) ${ }^{13}$, no veo cómo pudrías defender que se equivoca quien, habiéndote oído o leído, insiste en que eres seguidor estricto de DwORKIN o partidario del iusnaturalismo tomista. Es más, no sé ni cómo tienes ese ánimo entusiasta para meterte en polémicas cuando de antemano asumes que, digas lo que digas, te pueden entender como quieran y no hay base objetiva para imputar a los otros malas comprensiones o interpretaciones erróneas. ¿ $\mathrm{O}$ acaso lo que de objetivo haya en el lenguaje y su semántica, en las convenciones lingüísticas, no rige para el derecho? ¿Está el derecho hecho de otra sustancia? Eso es lo que piensa Manolo ATIENZA..., creo. ¿Son de otra sustancia, en general, los sistemas (jvade retro!) o conjuntos de reglas o normas?

Por cierto, permíteme un guiño sonriente, socarrón y malévolo: a la vista de tus tesis, espero que a estas consideraciones mías no vayas a responder reescribiéndome entrecomillado algún fragmento tuyo de este escrito que comento, ya que me bastaría contestarte que hay tantos escritos tuyos como interpretaciones diferentes demos a tu escrito (vid. los párrafos del núm. 8 en los que están las notas 20 y 21) ${ }^{14}$. Porque no te considero persona soberbia, y soberbio habría que ser para pensar que las palabras de un artículo tuyo tienen unos límites objetivos de significado de los que carecen las palabras de eso que llamamos «derecho positivo» (y que sabemos más o menos lo que es, pues es un hecho).

4. Si con el ejemplo de los significados posibles de tu obra o de tal o cual fragmento de la misma ya me he divertido y desconcertado, entre otras cosas porque un seguidor tuyo me haría muy serias objeciones cada vez que yo por ejemplo dijera «el sistema teórico del profesor Haba», o el «sistema conformado por la obra del profesor Haba», apelando así a la idea de sistema, «disimulante entelequia» ${ }^{15}$, ahora enredemos un rato con otro ejemplo.

Imaginemos que me llega la noticia de que un juez costarricense te ha condenado a muerte a ti (¡No lo quieran los hados, maldición!) y que a mí lo primero que se me ocurre preguntarle a ese interlocutor que me da la noticia y que es fiel seguidor de tus tesis es lo siguiente: ¿pero hay pena de muerte en el sistema jurídico costarricense? A lo que él me replicaría que deje de usar entelequias engañosas y que los sistemas jurídicos

\footnotetext{
12 Loc. cit., 359 (a la altura de la n. 19).

13 Ibid.

14 Loc. cit., 360.

15 Loc. cit., 361 (en el párrafo que sigue a la división ***).
} 
son entidades inexistentes, como ya ha visto hasta ATIENZA. Entonces yo, más preocupado por el problema de fondo a tu persona concerniente que por estas pendejadas doctrinales, le respondo que quiero decir que si en el derecho de Costa Rica hay alguna norma que permita condenar a muerte a algún acusado de algo. Él me dice, en buena lógica, que si pretendo usar «derecho de Costa Rica» como sinónimo de «sistema jurídico de Costa Rica», vuelvo a ser el mismo idealista impenitente y errado.

¡Ya no sé qué hacer! Si le pregunto si alguna vez algún juez condena a alguien a muerte en Costa Rica en estos tiempos, ¡me tendrá que responder que sí!, ya que un juez acaba de condenarte a esa pena a ti. Entonces yo me quedo interrogándome sobre: a) si tiene en verdad sentido que yo trate de recurrir (supóngaseme la legitimidad) contra la condena tuya basándome en lo que dispone el «sistema» jurídico de Costa Rica (;pero si recurro basándome en una norma del derecho vigente en Uzbequistán me van a contestar que esa norma no es del «sistema» costarricense! ¡Querrán volverme loco!), pues, te salve o no, tú siempre pensarás que si ganamos fue porque los engañé, ya que los sistemas jurídicos propiamente no existen; b) si debo citar alguna norma, del tipo de una que dijera (imaginemos que la hay) «Queda abolida en Costa Rica la pena de muerte en todo caso para toda clase de delitos», y dado que, por mucho que yo me empecine en que comparecen ahí unos límites de significado o de interpretaciones posibles, tú estarías pensando que no y que sigo tratando de engañar a todo el mundo con el buen ánimo de salvarte; c) si no deberé más bien comprar o seducir (esto último en la modesta medida de mis posibilidades e inclinaciones) a los miembros y «miembras» del tribunal que haya de ver el recurso contra la sentencia que te condena, mas en caso de que así haga y prospere mi gestión, me preguntaré si es que hice valer el derecho vigente o si del derecho vigente formará parte también el dinero que pagué a los magistrados varones y las variadas deferencias que me permití con la única magistrada. Bueno, yo en cualquier caso estaría feliz de que siguieras con vida, pero creo que cambiaría de oficio. De hecho, creo que cambiaré de oficio, porque es triste que siga sin saber lo que es el derecho a estas alturas y que, para colmo, algún autor de los que más aprecio me insista en que no existe apenas y que si existe va a ser peor.

En una cosa estoy bastante de acuerdo contigo: sí que son más abundantes de lo esperable las coincidencias entre tú y Manolo. Lo cual, por cierto, me alegra, pues sois, ambos dos, amigos para mí muy queridos, y siempre resulta estimulante que los amigos de uno se entiendan y compartan cosas. Lo que me apena es que seguramente ambos me rechazaríais como abogado si tuvierais un pleito, visto mi empeño en el sistema jurídico, sus normas «positivas» y sus significados posibles. Ninguno de los dos vería con buenos ojos mi insistencia en defender que no se os puede condenar por hacer $\mathrm{X}$ si la norma jurídica clara y terminantemente dice que $\mathrm{X}$ está permitido y que no cabe condena por X. Manolo prefería ser condenado que no que nos embarcáramos en formalismos, siempre y cuando que la condena suya le pareciera justa a él mismo (y al auditorio universal, por supuesto; aunque nunca me lo he encontrado discutiendo con el auditorio universal y suele más bien tenerlo de su parte, no sé por qué), más allá de la letra de la ley y de todas esas añagazas de positivista. Y tú te habrías resignado desde el principio a que cualquier cosa podría pasar, dada la cantidad de factores conductuales que concurrirían, ya que ni hay sistemas jurídicos ni límites objetivos a la interpretación de las normas, ni siquiera de las que nos favorecen, y puesto que no soportarías el empeño de tu abogado en fingir esencialismos y en perpetrar novelerías. Y fíjate, yo 
por ganar el caso en beneficio de cualquiera de vosotros hasta estaría dispuesto a ponderar siguiendo estrictamente las pautas de ALEXY. Enésima prueba de mi frivolidad de jurista novelero e irredento idealista.

5. Creo que buena parte del equívoco o la discrepancia a propósito de la interpretación sobre mi texto proviene de lo que podríamos llamar el alcance de mi pretensión de objetividad para la interpretación de las normas jurídicas. Dices lo siguiente (núm. 8, párr. 2. ${ }^{\circ}$ :

Mas vuestra presentación del asunto [...] aparece basada en, y dirigida hacia, el esfuerzo intelectual por hallar claves capaces de justificar la creencia en una inveterada cuadratura del círculo: la postulación de que puede haber unos criterios propiamente objetivos, ya sean unos u otros, para dirimir los conflictos de interpretación entre los juristas ${ }^{16}$.

La pretensión de objetividad interpretativa que yo puedo abrigar podríamos llamarla negativa. No sostengo que de entre las interpretaciones posibles haya una que pueda demostrarse como la objetivamente verdadera y única verdadera, como la única interpretación correcta de entre las interpretaciones posibles. Lo que mantengo es que hay interpretaciones objetivamente imposibles. Serían aquéllas que asignan a un término o una expresión un significado «imposible», en cuanto patentemente incompatible con los sentidos que una comunidad lingüística puede asignar a ese término o expresión en un determinado campo de la comunicación. Si tú me dices que dentro de un rato vas a «darle de comer al gato», yo yerro por completo si entiendo o interpreto que me estás transmitiendo la información de que te vas a duchar con agua fría. Otra cosa es que pueda tener variados alcances o interpretaciones lo que sea «darle de comer al gato». Puede haber a propósito de tu expresión un conflicto de interpretaciones, pero una de las interpretaciones en conflicto no podrá ser la de que te vas a duchar con agua fría. Por supuesto, dejo de lado la posibilidad de que tú y yo estemos utilizando un lenguaje en clave nuestra o extrañamente encriptado.

¿Por qué no es objetivamente posible esa interpretación? De hecho cabe, yo puedo entender tal cosa en tus palabras, pero cualquiera me indicaría que o he oído mal, o desconozco nuestro común idioma o no estoy en mis cabales.

Naturalmente que podemos señalar una «zona de penumbra» entre interpretaciones posibles e interpretaciones imposibles. Es evidente que es imposible la interpretación de la ducha que he mencionado y es evidente que es posible que yo interprete que a tu gato le vas a poner comida en un plato. A lo mejor sucede que tu gato está enfermo, no puede comer, y le vas a administrar alguna sustancia alimenticia mediante una sonda o con una inyección y lo expresas así, en sentido un tanto figurado, como que vas a «darle de comer al gato». Tampoco pretendo que entre las interpretaciones posibles y las imposibles haya una frontera completamente nítida y perfectamente tangible. Sólo digo que hay interpretaciones imposibles, significando que son palmariamente erróneas, no que algún chiflado no pueda hacerlas o que no pueda ser un juez ese chiflado.

Una norma procesal puede disponer que el plazo para la presentación de determinado tipo de demanda es de quince días, y podemos debatir sobre si será mejor in-

16 Loc. cit., 358. 
terpretar que esos quince días son naturales o que son laborables. Pero si, sólo con esa norma en mano y sin ninguna otra que justifique la excepción, un juez admitiera la demanda presentada a los 200 días y alegara que donde la norma dice «quince» también se puede entender «doscientos», no estaría haciendo una interpretación propiamente dicha, una de las posibles. Estaría creando otra norma, y eso sería legítimo o no según la concepción del derecho que se maneje.

Me dirás que los jueces a veces hacen eso. Yo te reconozco que así es, de becho, pero añado dos cosas. Una, que cuando se interpreta una norma y se elige una de las interpretaciones posibles (según mi noción), se está aplicando (mejor o peor, ahí vendrán opiniones) esa norma y, por tanto, el juez se atiene a su obligación de aplicar derecho y no de disponer lo que a él libérrimamente le plazca. Y dos, que los iusmoralismos tan en boga sirven para que el juez pueda «aplicar» las normas de esa forma que no halla límite alguno en su semántica, pues bastará que se aduzca que se está haciendo con la norma la debida justicia al caso para que se considere que el derecho está bien aplicado aunque la interpretación hecha propiamente fuera imposible. A lo mejor algún «realista» piensa que si así se aplica el derecho será porque ese derecho así es, opinión que el iusmoralista agradecerá a su manera, con unas bendiciones.

Así pues, entre mi modesta pretensión (negativa) de objetividad interpretativa de la interpretación y aplicación de las normas jurídicas y la pretensión de corrección de ponderativos y de iusmoralistas, que tiñen la práctica jurídica con su (pretendido) objetivismo moral, hay una distancia francamente grande, creo. Por el lado opuesto, mi postura estaría también alejada del apresurado (no es tu caso) «realista» que dijera que no hay por ningún lado diferenciación que valga entre interpretaciones posibles e imposibles de un enunciado, pues lo que pueda significar cualquier expresión queda absolutamente al albur del intérprete. Ese «realista» primitivo no debería perder su tiempo hablando con nadie, pues a cualquier interlocutor le estaría autorizando para pensar que sus proferencias, las del «realista», no tienen ningún significado intersubjetivamente descartable y que, por tanto, puede el interlocutor y cualquiera asignarles el significado que mejor se le antoje, sin límites o sin más límites que los empíricos y el fáctico temor a cosas tales como que el otro le propine un tortazo o que en su pueblo lo tomen por demente.

$$
* * *
$$

Lo dejo aquí, querido Enrique, ya se hace larga esta carta. Ha sido un placer. En estos debates contigo y con Manolo uno se siente felizmente acompañado, frente a ese mundo que ya en 1963 cantaba Edmundo Rivero, con letra de Mario BATTISTELlA, tango titulado «Bronca» y que bien conocerás, pues mucho sabes también de esas músicas:

\author{
Por seguir a mi conciencia \\ estoy bien en la palmera, \\ sin un mango en la cartera \\ y con fama de chabón. \\ Esta es la época moderna \\ donde triunfa el delincuente, \\ $y$ el que quiere ser decente \\ es del tiempo de Colón.
}


Lo cortés pasó de moda,

no hay modales con las damas,

ya no se respetan canas

ni las leyes ni el poder.

La decencia la tiraron

en el tacho 'e la basura

y el amor a la cultura

todo es grupo, puro bluff. 